\title{
PENGOLAHAN LIMBAH SANITASI BERBASIS BIO-ENERGI DALAM PENATAAN KAWASAN HUNIAN KUMUH DI TANJUNG DUREN UTARA, JAKARTA BARAT
}

\author{
Kayatsha Mutiara Nasser ${ }^{1}$, Timmy Setiawan $^{2)}$ \\ 1)Program Studi S1 Arsitektur, Fakultas Teknik, Universitas Tarumanagara, Kayatshansr@gmail.com \\ 2)Program Studi S1 Arsitektur, Fakultas Teknik, Universitas Tarumanagara, timmys@ft.untar.ac.id
}

\begin{abstract}
Abstrak
Gang Serketaris Tanjung Duren Utara, Jakarta Barat sudah menjadi pemukiman liar dari sebelum reformasi terjadi dan kini menjadi salah satu pemukiman dengan sanitasi terburuk di ibu kota. 124 kepala keluarga hidup berdampingan dengan bau tinja dari Kali Sekretaris yang membentang di sepanjang gang tersebut. Kesadaran warga yang rendah terhadap kebersihan dan pencemaran lingkungan membuat warga lebih memilih membuang kotorannya langsung ke Kali Sekretaris. Disisi lain, Indonesia juga mengalami krisis energi. menurut Wood Mackenzie Chemical and Energy Company, yang mencatat tren neraca energi Indonesia dari sisi batu bara, gas (LNG), dan minyak bumi, menyatakan Indonesia sudah mengalami defisit energi sejak 2007 dan semakin meningkat hingga perkiraan tahun 2040. Melihat keterkaitan antara permasalahan krisis energi dan permasalahan sanitasi di Indonesia, kedua hal ini secara tidak langsung dapat merusak suatu rantai ekologi namun apabila diselesaikan dengan tepat mampu membuka peluang pada pengembangan teknologi energi terbarukan maupun penyelesaian terhadap isu lingkungan yang terjadi. Proses Bio-energi dalam ranah arsitektur menjadi solusi penanganan Kawasan hunian kumuh untuk mencapai pemberdayaan sanitasi yang berkelanjutan. Bio-energi merupakan pengembangan energi terbarukan yang diperoleh dari biomassa. Rancangan program penataan kawasan hunian kumuh di Gang Sekretaris menggunakan pendekatan penulusuran kontekstual dari kondisi sosial budaya secara mendalam. Menciptakan sebuah komunitas sanitasi yang tercermin kepada kegiatan berhuni, bekerja, dan berkumpul.
\end{abstract}

\section{Kata kunci: Bio-Energi; Pemukiman Kumuh; Sanitasi}

\begin{abstract}
Gang Serketaris Tanjung Duren Utara, West Jakarta has been a squatter settlement since before the reform took place and is now one of the settlements with the worst sanitation in the capital. The 124 heads of families coexisted with the smell of sewage from the Secretary River that ran along the alley. The low level of public awareness of cleanliness and environmental pollution makes residents prefer to throw their waste directly into the Sekretaris River. On the other hand, Indonesia is also experiencing an energy crisis. according to Wood Mackenzie Chemical and Energy Company, which records the trend of Indonesia's energy balance in terms of coal, gas (LNG), and oil, stating that Indonesia has experienced an energy deficit since 2007 and continues to increase until it is estimated that in 2040. Seeing the link between the energy crisis and sanitation problems in Indonesia, these two things can indirectly damage the ecological chain but if resolved properly can open up opportunities for the development of renewable energy technologies and solutions to environmental problems. The bioenergy process in the realm of architecture is a solution for handling slum areas to realize sustainable sanitation empowerment. Bioenergy is the development of renewable energy obtained from biomass. The design of the slum area arrangement program at the Gang Secretariat uses a contextual search approach from deep socio-cultural conditions. Creating a sanitation community that is reflected in living, working, and gathering activities.
\end{abstract}

Keywords: Bio- Energy; Sanitation; Slum Area 


\section{PENDAHULUAN}

\section{Latar Belakang}

Permukiman kumuh berasosiasi dengan kualitas lingkungan permukiman buruk, ketidaknyamanan penduduk terhadap keamanan, dan kondisi sarana dan prasarana lingkungan tidak sesuai standar. Salah satunya ialah permasalahan sanitasi. Sanitasi pada lingkup kesehatan, sumber daya manusia dan ekonomi dapat memberikan dampak signifikan bila tidak diperhatikan dengan baik. Sebagai ibu kota, Jakarta belum bisa lepas dari masalah permasalahan sanitasi. Mengacu data Kementrian Kesehatan Republik Indonesia, sebanyak 30\% warga di Jakarta yang masih memiliki permasalahan sanitasi. Khususnya sebanyak 34.533 keluarga di Ibu Kota Jakarta masih berperilaku Buang Air Besar Sembarangan (BABS). Gang Sekretaris, RT 015/RW 007 Tanjung Duren Utara, Grogol Petamburan, Jakarta Barat, merupakan salah satu wilayah dengan sanitasi buruk. Sekitar $125 \mathrm{KK}$ terpaksa hidup dengan kondisi sungai yang tercemar.

Disisi lain, Indonesia juga mengalami krisis energi. menurut Wood Mackenzie Chemical and Energy Company, yang mencatat tren neraca energi Indonesia dari sisi batu bara, gas (LNG), dan minyak bumi, menyatakan Indonesia sudah mengalami defisit energi sejak 2007 dan semakin meningkat hingga perkiraan tahun 2040. Berbagai upaya dalam pengembangan energi terbarukan untuk menjamin ketersediaan kebutuhan energi di masa depan sudah mulai dilakukan. Contohnya dalam pemanfaatan aktivitas mikroorganisme dalam menguraikan senyawa-senyawa yang terbentuk dari limbah rumah tangga. Proses itu disebut bio-energi. Bioenergi berperan penting pada pencapaian target dalam menggantikan petroleum didasarkan pada bahan bakar transportasi dengan bahan bakar alternatif dan pereduksian emisi karbondioksida dalam jangka panjang. Melihat keterkaitan antara permasalahan krisis energi dan permasalahan sanitasi di Indonesia, kedua hal ini secara tidak langsung dapat merusak suatu rantai ekologi namun apabila diselesaikan dengan tepat mampu membuka peluang pada pengembangan teknologi energi terbarukan maupun penyelesaian terhadap isu lingkungan yang terjadi.

\section{Rumusan Permasalahan}

Isu yang telah dipaparkan memiliki beberapa masalah yang dapat dirumuskan untuk kelak menjadi acuan desain yaitu bagaimana mengembangkan Kawasan hunian kumuh yang peka terhadap kebersihan sanitasi?; bagaimana pemanfaatan limbah rumah tangga untuk proses bioenergi berskala hunian?; bagaimana program arsitektural dapat menjembatani kegiatan berhuni dan pengolahan bio-energi?

\section{Tujuan}

Tujuan proyek dalam penataan kawasan hunian kumuh melalui proses bio-energi sebagai upaya untuk memberikan ruang berhuni yang layak kepada penduduk dengan sarana dan prasarana yang lebih baik. Pengolahan bio-energi diaplikasikan sehingga dapat dimanfaatkan kembali energi maupun limbahnya untuk kehidupan sehari-hari dan difokuskan untuk pengembangan usaha masyarakat. Proyek ini juga difokuskan kepada pengembangan komunitas pengolahan bio-energi sendiri sehingga dapat beriringan dengan kehidupan sehari-hari.

\section{KAJIAN LITERATUR}

\section{Upaya Penanganan Hunian Kumuh}

Pemukiman Menurut Constantinos A. Doxiadis (1968: 21-35) terdapat lima elemen dasar pemukiman yaitu Nature atau alam (lahan yang dapat dimanfaatkan untuk membangun tempat tinggal maupun fungsi lainnya); Man atau manusia (baik pribadi maupun kelompok yang membangun atau bertempat tinggal); Society atau masyarakat (dimana di dalamnya terdapat interaksi dan hubungan sosial antar manusia sehingga membentuk ikatan tertentu sebagai masyarakat); Shells atau rumah (bangunan tempat tinggal manusia dengan fungsi masing- 
masing); Networks atau jaringan (sarana prasarana yang mendukung fungsi lingkungan baik alami maupun buatan manusia).

Dalam menangani pemukiman kumuh yang terbentuk, perlu melihat faktor yang telah disebutkan dalam solusi yang akan dihasilakan. Pemerintah Indonesia telah mengidentifikasikan beberapa isu strategis untuk mewujudkan kawasan permukiman yang layak huni dan berkelanjutan, diantaranya yaitu rendahnya layanan air minum aman, rendahnya layanan sanitasi yang layak, meluasnya kawasan kumuh, dan penanggulangan kemiskinan. Pelaksanaan pembangunan prasarana dan sarana dasar permukiman tersebut juga dilaksanakan dengan model pemberdayaan yang melibatkan masyarakat sejak perencanaan sampai dengan operasi dan pemeliharaan insfrastruktur, salah satu program yang diinisiasi oleh pemerintah untuk mewujudkan visi tersebut adalah Penataan Lingkungan Permukiman Berbasis Komunitas (PLPBK).

\section{Bio-Energi}

Bio-energi adalah energi yang diperoleh dari biomassa sebagai fraksi produk biodegradasi, limbah, dan residu dari pertanian (berasal dari nabati dan hewani), industri kehutanan dan terkait, dan sebagian kecil biodegradasi dari limbah industri dan kota. Bioenergi berperan penting pada pencapaian target dalam menggantikan petroleum didasarkan pada bahan bakar transportasi dengan bahan bakar alternatif dan pereduksian emisi karbondioksida dalam jangka panjang. Kelebihan bioenergi, selain bisa diperbaharui, adalah bersifat ramah lingkungan, dapat terurai, mampu mengeliminasi efek rumah kaca, dan kontinuitas bahan bakunya terjamin (Hambali et al., 2007).

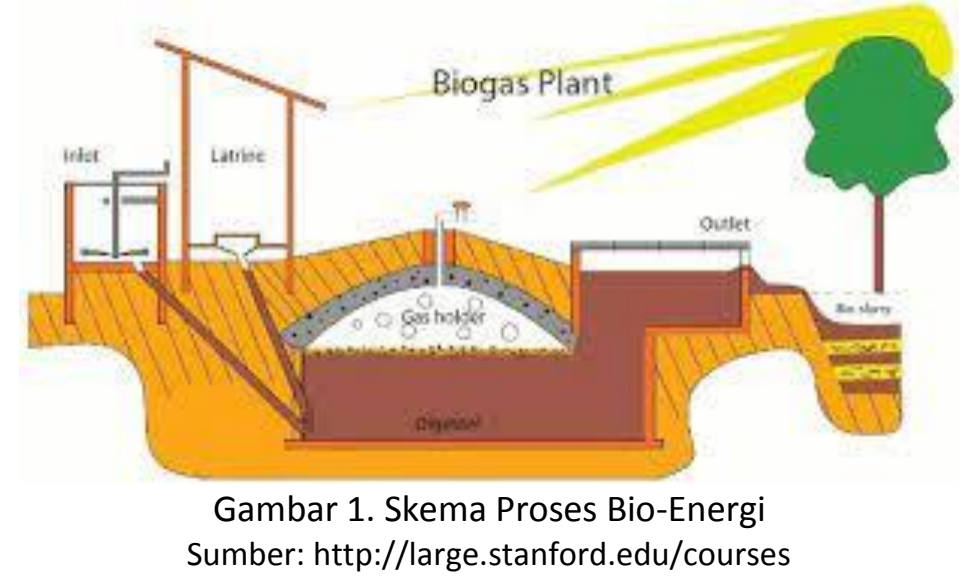

Dalam prosesnya, menggunakan peran mikroorganisme dalam penguraian senyawa metan (CH4) yang terkandung dalam kotoran. Proses ini dilakukan didalam chamber/ tangki yang berada didalam tanah. Hasil dari proses fermentasi menghasilkan lumpur yang mengendap. Lumpur ini dapat digunakan sebagai penyubur tanah/ organic fertilizer pada area perkebunan yang ramah lingkungan sehingga tidak hanya aman untuk lingkungan namun baik untuk kualitas tanaman yang akan dihasilkan.

\section{METODE}

Rancangan program penataan kawasan hunian kumuh di Gang Sekretaris menggunakan pedekatan arsitektur simbiosis. Arsitektur berdasarkan filsafat simbiosis adalah pendekatan yang diwujudkan dengan menelusuri akar sejarah dan budaya secara mendalam, dan di saat yang sama berusaha untuk menggabungkan (unification) elemen-elemen dari budaya lain dalam karyanya, sehingga terjadi gabungan antara dua elemen langgam budaya yang berbeda (Ikhwanuddin, 2005:73). Untuk metode perancangan desain menggunakan pendekatan kontekstual terhadap konteks berhuni dan karakter tempat. Menurut Brent C. Brolin (1980), 
kontekstualisme adalah keinginan mengkaitkan bangunan baru dengan lingkungan sekitarnya. Seorang arsitek atau perencana bangunan dianjurkan untuk memperhatikan dan menghormati lingkungan fisik sekitarnya, mengutamakan kesinambungan visual antara bangunan baru dengan bangunan, landmark, bahkan gaya setempat yang keberadaannya telah diakui sebelumnya. Pendekatan ini akan berpengaruh kepada fasilitas publik yang akan dirancang, desain hunian yang dibutuhkan, dan konfigurasi ruang.

\section{DISKUSI DAN HASIL}

\section{Kontekstual Tapak}

Gang Serketaris Tanjung Duren Utara, Jakarta Barat sudah menjadi pemukiman liar dari sebelum reformasi terjadi dan kini menjadi salah satu pemukiman dengan sanitasi terburuk di ibu kota. 124 kepala keluarga hidup berdampingan dengan bau tinja dari Kali Sekretaris yang membentang di sepanjang gang tersebut. Penyebabnya ialah kondisi perekonomian warga yang tidak mampu memasang instalasi pembuangan/ septic tank. Kesadaran warga yang rendah terhadap kebersihan dan pencemaran lingkungan membuat warga lebih memilih membuang kotorannya langsung ke Kali Sekretaris.

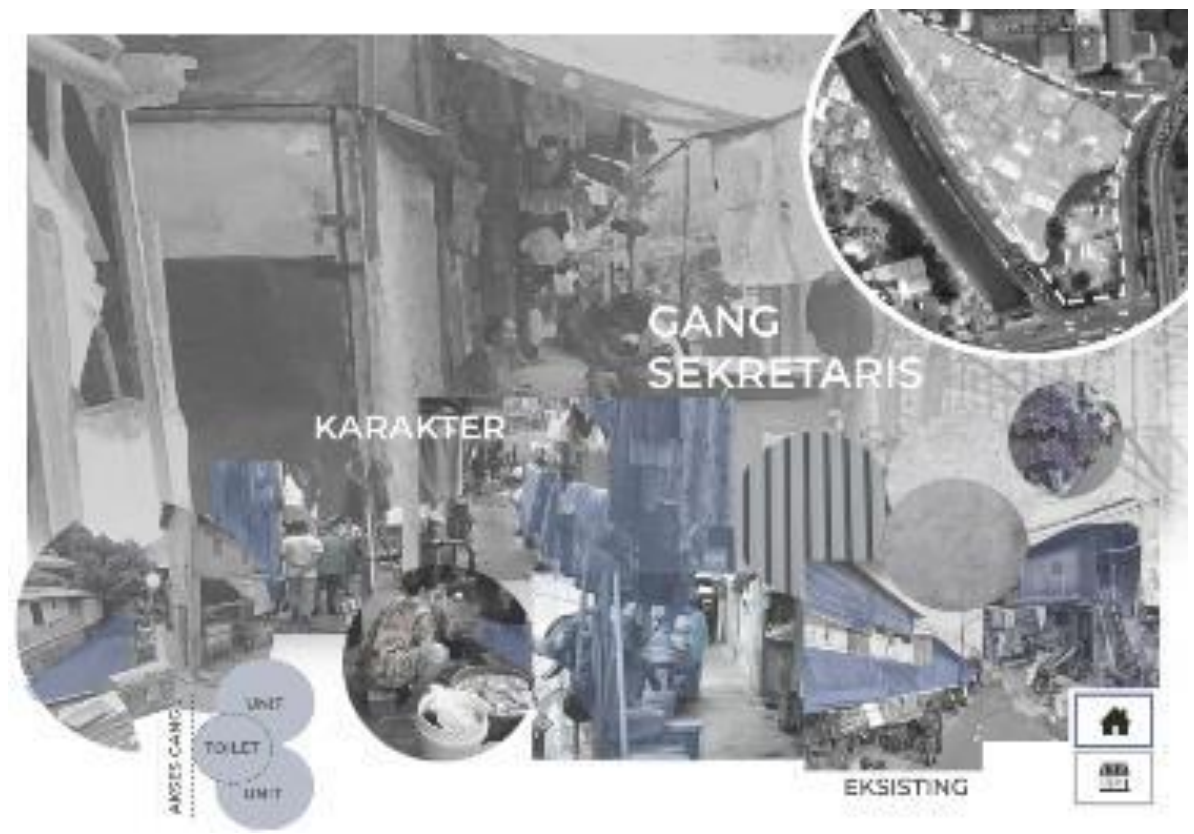

Gambar 2. Kolase Situasi Gang Sekretaris

Sumber: Penulis, 2021

Kondisi perekonomian warga sekretaris yang rendah menyebabkan warga harus berbagi fasilitas toilet dengan kapasitas satu toilet untuk tiga hingga kepala keluarga. Jumlah sanitasi yang tidak sesuai standar tentunya mempengaruhi kesehatan dan produktivitas warga setempat. Toilet juga terletak dibagian depan hunian untuk mempermudah akses bersama. Selain itu agar pipa pembuangan dapat langsung diarahkan menuju Kali Sekretaris. Akses gang yang hanya selebar dua meter tersebut tidak hanya digunakan sebagai akses sirkulasi namun sebagai area komunal, area penyimpanan, dan service (karena posisi kamar mandi yang berada di area depan hunian). Hal ini menyebabkan aktifitas di gang serketaris menjadi padat, diikuti lagi posisi sungai yang tercemar memaksa warga Gang Serketaris untuk beraktivitas dengan bau tinja yang menguap. 

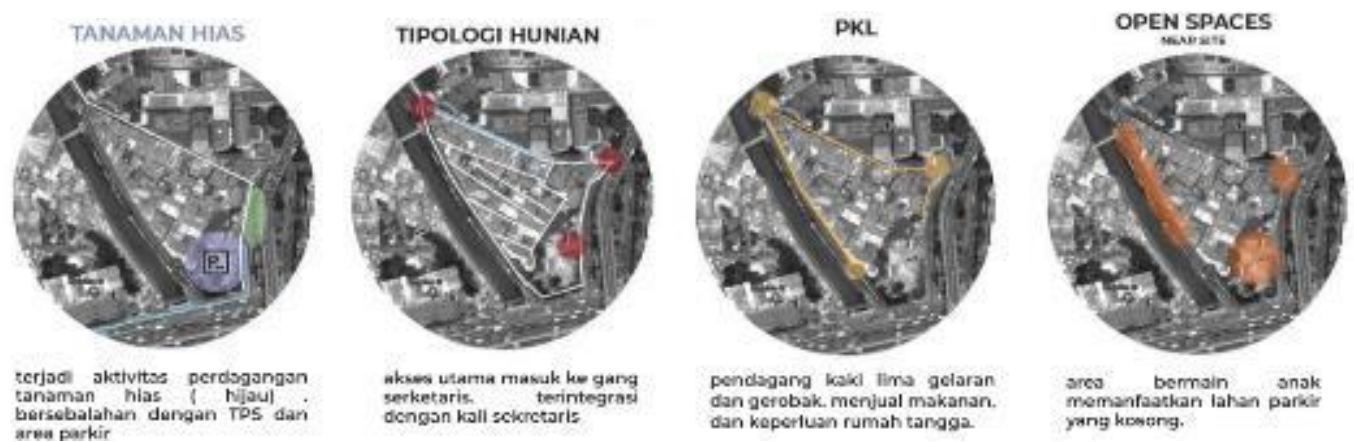

Gambar 3. Mapping Aktivitas di Sekitar Gang Sekretaris Sumber: Penulis, 2021

Aktivitas utama warga selain berhuni ialah berdagang. Masyarakat memanfaatkan area pinggir jalan untuk memasang etalase makanan, terdapat PKL yang juga menggelar dagangannya di trotoar jalan, tidak hanya makanan tapi beberapa titik di Gang Sekretaris juga dijadikan sebagai area retail tanaman hias. Rumah yang berada dipinggir Jalan Sekretaris menggunakan lantai dasarnya untuk berdagang, sedangkan aktivitas berhuni dilakukan dilantai dua.

\section{Pembentukan Program}

Usulan program dibentuk dengan mengacu kepada The Bellagio Principle Water Supply and Sanitation Collaborative Council 2000. Terdapat empat langkah untuk menciptakan sanitasi berkelanjutan khususnya pada daerah perdesaan maupun hunian kumuh. Dengan pendekatan metode simbiosis, strateginya ialah menciptakan program komunitas bio-energi dimana energi yang dihasilkan dapat digunakan untuk kebutuhan memasak dan limbah yang dihasilkan dapat digunakan untuk pengembangan Usaha Mikro Kecil dan Menengah (UMKM). Digabungkan dengan program living and community dengan tujuan memperbaiki kualitas berhuni dari segi luasan ruang dan ketersediaanya sarana dan pra-sarana yang sesuai, tanpa meninggalkan kondisi sosial dan budaya yang telah ada. Berikut dibawah ini merupakan skema pembentukan program.

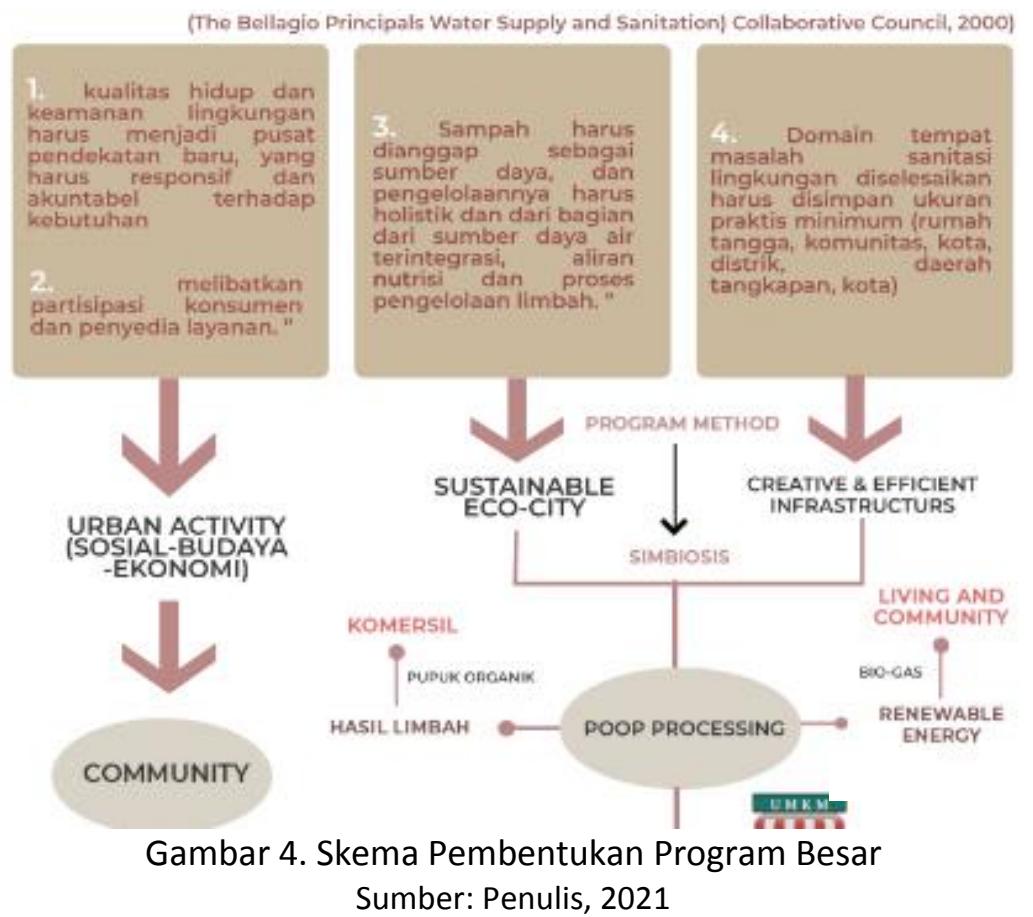




\section{Proses Bio-gas}

Jumlah biogas yang dapat diekstrak dari sampah organik bergantung pada limbah itu sendiri dan desain sistem digester. Beberapa digester dapat menghasilkan $20 \mathrm{~m} 3$ biogas per ton limbah sementara yang lain dapat menghasilkan sebanyak $800 \mathrm{~m} 3$ per ton tergantung pada kualitas limbah, desain digester dan pengoperasian sistem yang tepat. Setiap $1 \mathrm{~m} 3$ biogas memungkinkan untuk memasak hingga tiga kali makan untuk keluarga yang terdiri dari lima hingga enam orang atau untuk mengoperasikan bohlam 60-100 W selama enam jam (Andriani, D. et al, 2015: 219-225).

\section{Rancangan Konsep Massa}

Dengan menggunakan metode desain konseptual, perancangan bangunan mengadaptasi pada kondisi eksisting pemukiman sekitar. Pola sirkulasi, aksesibilitas, zoning aktivitas, pencegahan resiko kebakaran menjadi acuan utama desain.
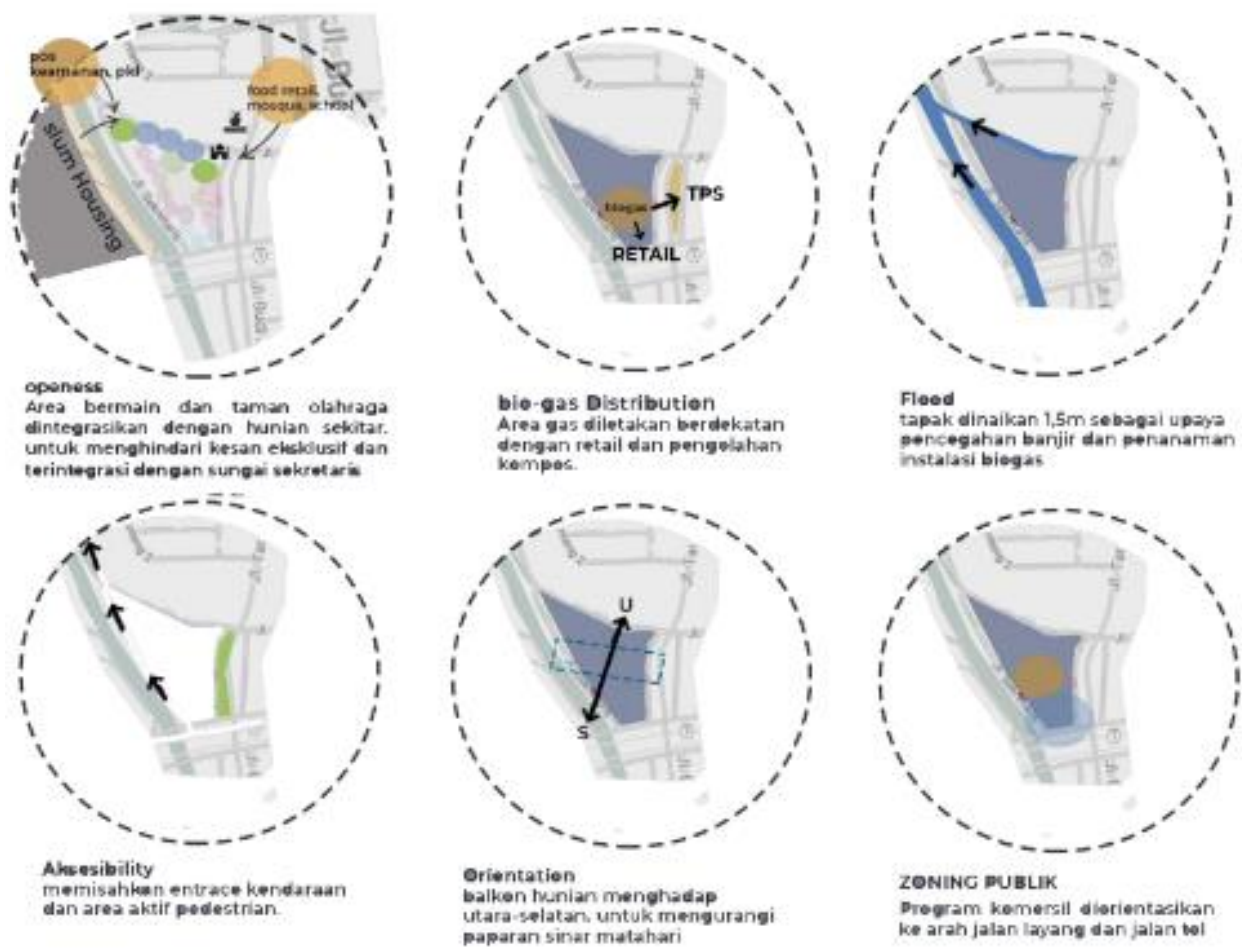

Gambar 5. Respon Site Terhadap Kondisi Eksisting Gang Sekretaris Sumber: Penulis, 2021

Kawasan disekitar tapak merupakan kawasan pemukiman dengan tingkat pendapatan rendah. Fasilitas ruang terbuka minim di daerah tersebut. keterbatasan lahan membuat warga terbiasa berbagi ruang publik sehingga kehidupan bertetangga di gang tersebut erat. Maka peracangan ruang publik dibuat terbuka kesekitar pemukiman Gang Sekretaris. Berbagi Ruang publik juga menjadi salah satu strategi komersil untuk pengembangan UMKM. Kawasan gang serketaris yang memiliki KLB $40 \%$ dan KDH 30\% secara geografis kawasan ini rendah sehingga rawan terjadi banjir, sehingga tapak dinaikan $1,5 \mathrm{~m}$ dan pemaksimalan lantai dasar sebagai area resapan. Peruntukan lantai dasar untuk area-area terbuka publik. Seperti retail makanan, retail tanaman dan kompos, ruang bermain anak, area olahraga, dan parkir. 


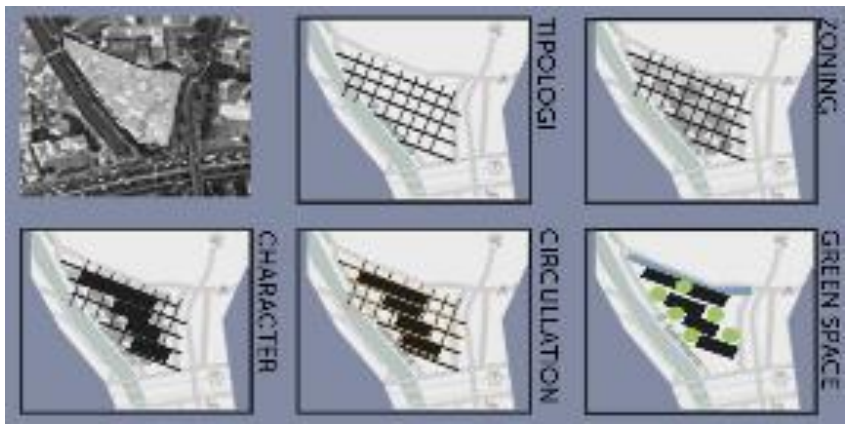

Gambar 6. Proses Pembentukan Massing

Sumber: Penulis, 2021

Bentuk massa mengikuti tipologi hunian eksisting. Setelah itu pembentukan massa bedasarkan sifat ruang dibentuk. Lantai dasar dibuat semi-outdoor dengan penggunaan partisi seminim mungkin dan diperuntukan untuk umum. Sedangkan unit hunian dan fasilitas yang eksklusif di letakan dilantai dua hingga empat. Pola sirkulasi searah dengan axis, mengikuti khas hunian di dalam gang. Tiap massa dibuat merenggang sekitar 6 meter yang dapat dimaksimalkan sebagai area hijau dan area berkumpul.

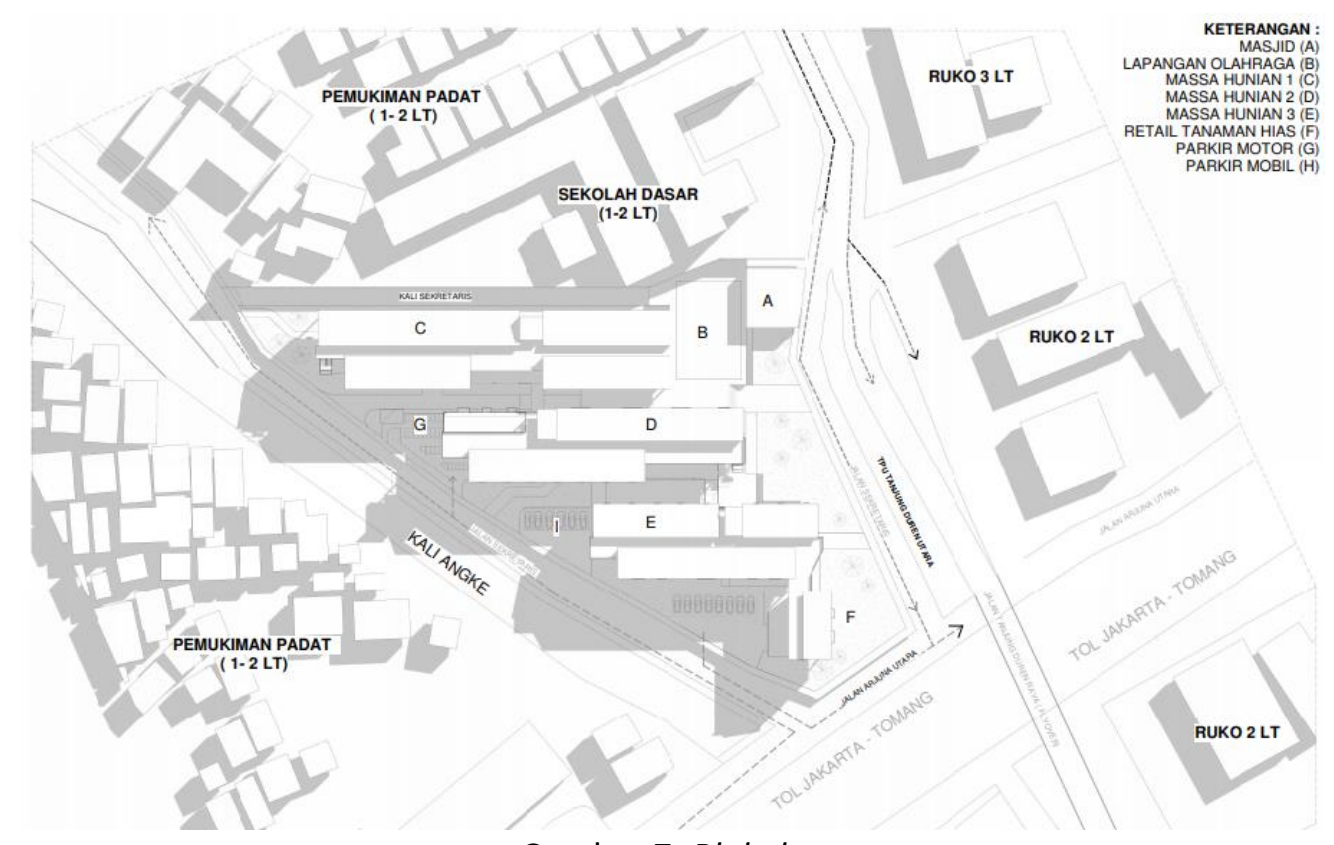

Gambar 7. Blokplan

Sumber: Penulis, 2021

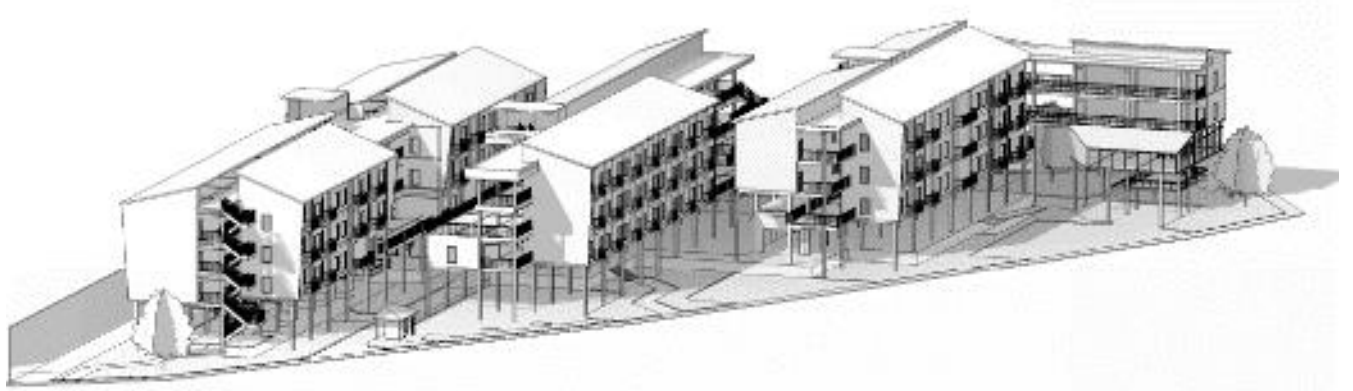

Gambar 8. Perspektif (Bentuk Akhir Massa)

Sumber: Penulis, 2021 


\section{Rancangan Struktur Unit, Fasad, dan Utilitas}

Sistem struktur menggunakan sistem modular $6 \times 6$ yang disesuaikan dengan desain unit hunian dengan tipe 1BR (satu kamar tidur) dengan luas $36 \mathrm{~m}^{2}, 2 \mathrm{BR}$ (dua kamar tidur) dengan luas $42 \mathrm{~m}^{2}$, dan 3BR (tiga kamar tidur) dengan luas $54 \mathrm{~m}^{2}$. Ketersediaan Unit di Hitung bedasarkan pemaksimal luas KDB. Total hunian yang didapat sebanyak 145 hunian dengan tipe Tipe 1BR sebanyak 45 unit, 2BR sebanyak 54 unit, dan 3BR sebanyak 21 unit. Untuk memaksimalkan lahan pada tiap hunian, area berkumpul difokuskan berada diluar hunian. Mengikuti kebiasaan masyarakat yang berkumpul di luar rumah. Namun disediakan ruang yang dapat disesuaikan dengan kebutuhan privasi pengguna (dapat digunakan sebagai ruang makan dan atau ruang keluarga).


Gambar 9. Denah Unit

Sumber: Penulis, 2021

Desain Fasad menggabungkan material kayu Cross Laminated Timber (CLT) dengan konstruksi beton dan balok beton. CLT merupakan dinding kayu yang ramah lingkungan dan tahan lama berada di iklim tropis. Penggunaan material kayu pada lantai dan partisi untuk memberikan kesan "kampung" pada ruang-ruang publik.

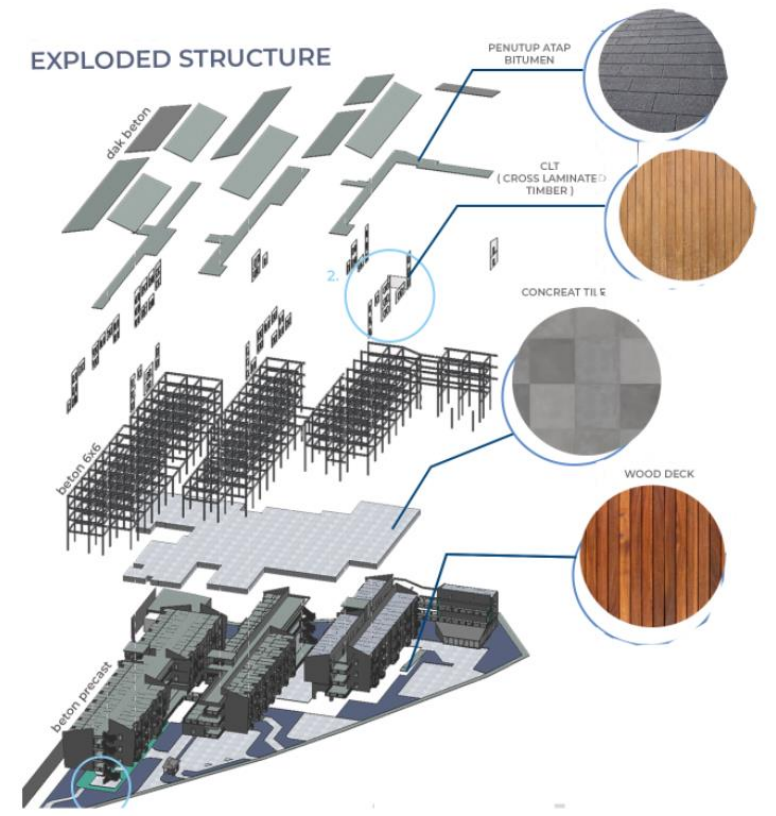

Gambar 10. Exploded Structure Sumber: Penulis, 2021 


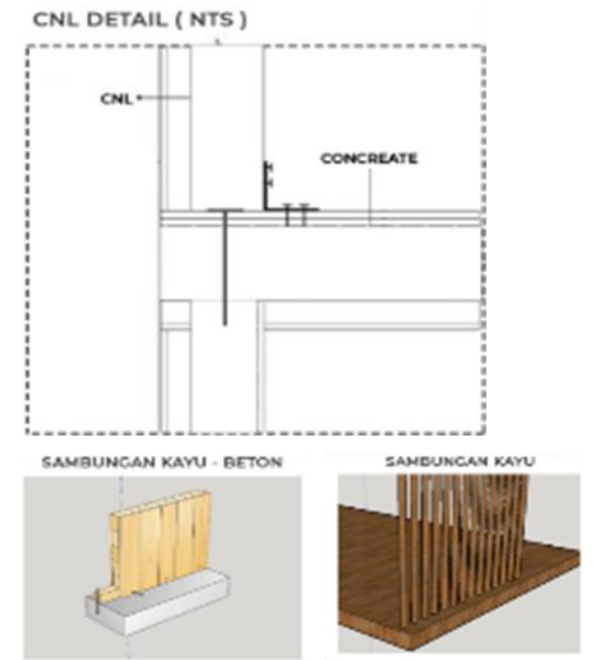

Gambar 11. Cross Laminated Timber Detail

Sumber: Penulis, 2021

Sistem Pengolahan Bio-gas menggunakan sistem shaft. Kotoran ditampung terlebih dahulu di dalam tangki dimana akan tercampur telebih dahulu dengan air bekas pakai dan air hujan. Setelah itu akan disalurkan kedalam tangki bio-gas untuk proses fermentasi yang menghasilkan gas. Gas akan menguap keatas permukaan tangki dan memasuki pipa yang dihubungkan langsung ke retail dan dapur bersama melalui plafon. Hasil dari proses fermentasi merupakan lumpur yang mengendap. Lumpur tersebut dapat disalurkan ke tangki slurry pit sehingga dapat dimasukan kedalam mobil tangki atau kedalam kemasan kompos cair.

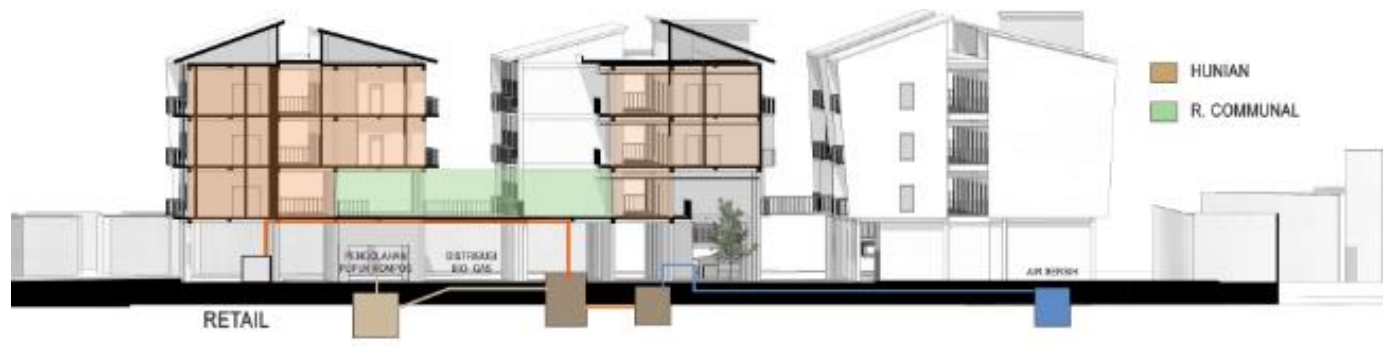

Gambar 12. Skema Alur Bio-Gas

Sumber: Penulis, 2021

\section{Perancangan Ruang Publik}

Area instalasi bio-gas didesain terbuka agar tidak hanya menjadi sebagai area servis tapi dapat dimanfaatkan sebagai ruang publik. Selain itu sebagai sirkulasi udara untuk mencegah ledakan gas. Partisi pembatas bambu untuk menjauhkan instalasi bio-gas dari jangkauan anak-anak. Gambar 13 menunjukan selasar yang menghubungkan dapur umum dan area instalasi bio-gas.

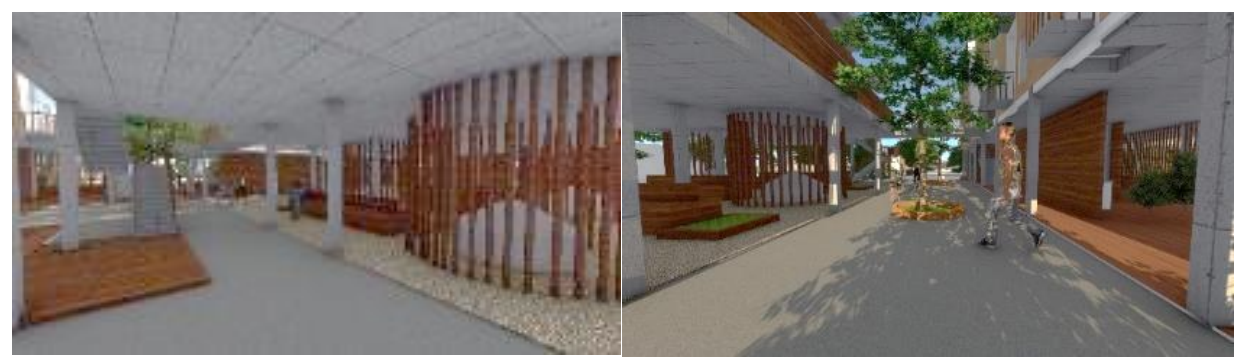

Gambar 13. Instalasi Bio-Gas

Sumber: Penulis, 2021 
Menaikan Hunian di Lantai atas memberikan ruang yang lebih luas terhadap sirkulasi antara jalan dan kali sekretaris. Lantai dasar dimanfaatkan sebagai area bermain anak dan working space. Ruang hijau juga dapat dimanfaatkan untuk area berjualan PKL. Gambar 14 menunjukan desain area bermain anak yang berada dibawah ruang working space. Disesuaikan dengan tinggi anak. Area ini juga bisa digunakan untuk area duduk. Mengikuti kebiasaan berkumpul warga gang sekretaris dengan tetap mempertahankan ciri khas berkumpul di pinggir kali. Ruang publik juga dibuat dilantai unit hunian. Ruang publik tersebut dikhususkan bagi pemilik unit. Area ini bisa digunakan untuk working space dan outdoor cooking. Desain Balkon juga dibuat tanpa menghilangkan kesan bertetangga.
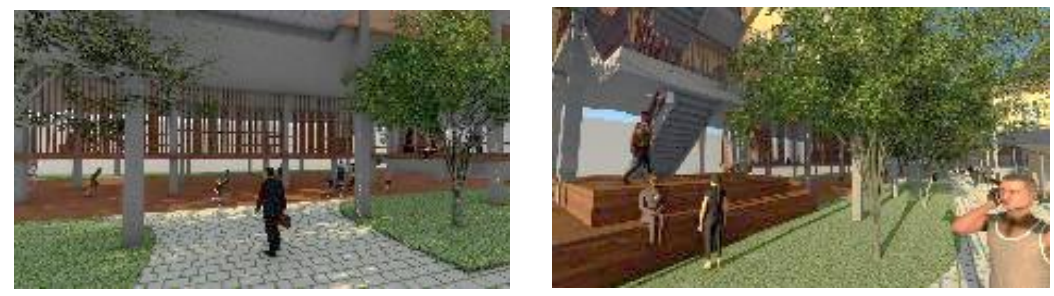

Gambar 14. Area Hijau di Sekitar Ruang Bermain Anak dan Working Space Sumber: Penulis, 2021
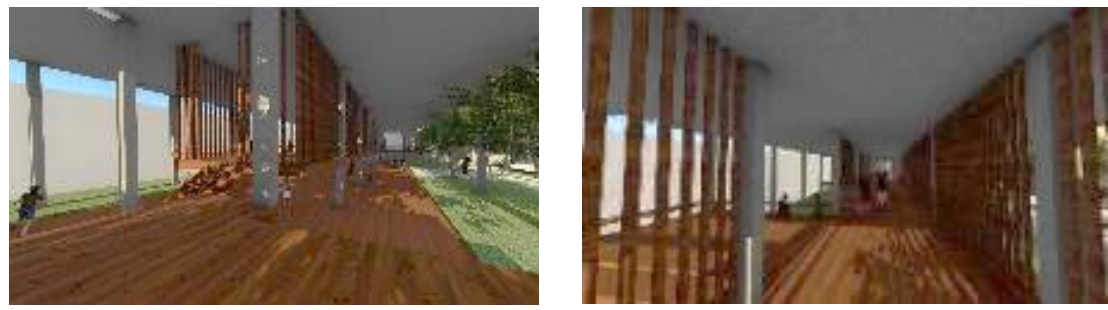

Gambar 15. Co-working Space

Sumber: Penulis, 2021
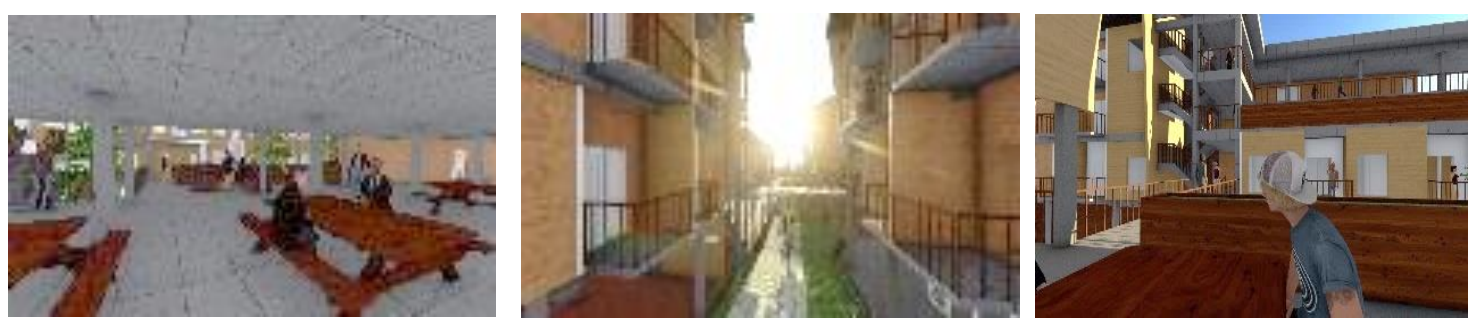

Gambar 16. Area Publik pada Tiap Lantai Hunian

Sumber: Penulis, 2021

\section{KESIMPULAN DAN SARAN Kesimpulan}

Penataan kembali kawasan kumuh yang mengedepankan aspek kesadaran akan kebersihan sanitasi tidak hanya dengan kembali membangun hunian baru dengan fasilitas toilet yang memadai namun juga memberikan kesadaran dengan pentingnya merawatnya secara bersama agar nyaman digunakan. Hal ini dapat dilakukan dengan memaksimalkan peruntukan ruangruang publik pada area servis. Dengan pengembangan ilmu teknologi, Sanitasi juga dapat digunakan untuk meningkatkan perekonomian masyarakat berpendapatan rendah melalui program usaha mikro, kecil, dan menengah (UMKM). Hal ini juga dapat memberikan kesadaran terhadap warga Gang Sekretaris bahwa sanitasi menjadi bagian dari kegiatan berhuni, berkumpul, dan bekerja. Program pengolahan limbah rumah tangga juga tidak hanya menjawab isu kebersihan lingkungan namun dapat meningkatkan efektivitas penggunaan energi yang ramah lingkungan. 


\section{Saran}

Diharapkan dapat dilakukan studi lebih lanjut mengenai aplikasi instalasi bio-gas pada skala hunian vertikal dan dampaknya terhadap pemukiman di kota-kota besar. Khususnya pemukiman kumuh yang merupakan pembentukan hunian liar dari kondisi hunian di perdesaan. Pengolahan limbah rumah tangga menjadi energi ramah lingkungannya sebaiknya dapat menjadi kajian ulang bagi pemerintah untuk program-program pentaan kawasan kumuh.

\section{REFERENSI}

Amintharso, Z. (2015). Penataan Pemukiman Kumuh di Kawasan Pesisir Berbasis Masyarakat Studi Kasus Desa Kalibuntu Kecamatan Kraksaan Kabupaten Probolinggo. Fakultas Teknik Sipil dan Perencanaan Institut Teknologi Nasional Malang.

Andriani, Dian, et. al. A review of recycling of human excreta to energy through biogas generation: Indonesia case a Research Center for Electrical Power and MechatronicsIndonesian Institute of Sciences. Komplek LIPI Bandung: Bandung 40135 - Indonesia

Andriani, D, et. al. (2015). A review of recycling of human excreta to energy through biogas generation: Indonesia case. Energy Procedia, 68, 219-225.

Kustiasih, T., Medawati, I. (2017). Kajian Potensi Gas Metan ( $\mathrm{CH}^{4}$ ) Dari Pengolahan Air Limbah Domestik Sebagai Upaya Mitigasi Emisi Gas Rumah Kaca. Research Methane Gas Potential From Wastewater Domestic Processing As Effort Mitigation Emission Of Greenhouse Gases., 52(1).

Makhfudli, Rachmawati, P. D. (2017). Factor Related to Open Defacation Behavior Among Schoolage Children in West Lombok. Jurnal Ners, 12(1), 119-125.

Raisya, N. (2015). Kajian Karakteristik Kawasan Pemukiman Kumuh di Kampung Kota (Studi Kasus: Kampung Gandekan Semarang. Jurnal Teknik PWK, 4(2).

S. Esfandiari, et al. (2011). Greenhouse Gas Emissions Reduction through a Biogas Plant: A Case Study of Waste Management Systems at FEKA Dairy Farm in 2nd International Conference on Environmental Science and Technology. Singapore.

Budy, A., Fredy, Penataan Kawasan Pemukiman Kumuh Kelurahan Tamamaung Kota Makassar, Jurnal Arsitektur, Kota dan Permukiman (LOSARI), https://media.neliti.com/media/publications/317102-penataan-kawasan-pemukimankumuh-kelurah-09065bd4.pdf

Pathak, B., 2014, Biogas Technology-Community Toilet Linked Biogas Plant, http://www.sulabhinternational.org/content/biogas-technology.

Suparjo R., 2020, Hadapi Krisis Energi, Pertamina Sudah Siapkan Resep Antisipasi, diunduh 21 Oktober 2020, https://ekbis.sindonews.com/read/203708/34/hadapi-krisis-energipertamina-sudah-siapkan-resep-antisipasi-1603278618 
